\title{
Improvement of power efficiency of hybrid white OLEDs based on p-i-n structures
}

\author{
Apisit Chittawanij $^{1}$, Kitsakorn Locharoenrat ${ }^{1}$
}

\author{
${ }^{1}$ Department of Physics, Faculty of Science, King Mongkut's Institute of Technology Ladkrabang, Bangkok 10520, Thai- \\ land \\ e-mail: apisit.ch@kmitl.ac.th, kitsakorn.lo@kmitl.ac.th
}

\begin{abstract}
In this article, hybrid white organic light-emitting diodes (WOLEDs) under p-i-n structures have been investigated in terms of power efficiency. By using tris(8-hydroxy quinolinato) aluminum ( $\left.\mathrm{Alq}_{3}\right)$ doped with 8-hydroxy-quinolinato lithium (Liq) as an n-type and WHI112 doped with molybdenum trioxide $\left(\mathrm{MoO}_{3}\right)$ as a p-type, the typical device structure of ITO/WHI112: $20 \mathrm{wt} \% \mathrm{MoO}_{3}(55 \mathrm{~nm}) / \mathrm{HTG}-1$ (10 nm)/UBH15: 3 wt.\% EB502 (10 nm)/EPH31: 3 wt.\% EPY01 (25nm)/3TPYMB (10 nm)/Alq 3 : 33 wt.\% Liq (25 nm)/Al (150 $\mathrm{nm}$ ) was fabricated. It has been found that the $\mathrm{p}$-i-n device based device showed the lowest driving voltage and highest power efficiency among the undoped and n-type devices. At the current density of $20 \mathrm{~mA} / \mathrm{cm}^{2}$, the roll-off of the efficiency in the p-i-n device was much smaller than the n-type and the undoped devices. The current and power efficiency of the p-i-n device were maintained with $17.2 \mathrm{~cd} / \mathrm{A}$ and $5.1 \mathrm{~lm} / \mathrm{W}$ at 100 $\mathrm{mA} / \mathrm{cm}^{2}$, it was reduced to $7.5 \%$ and $21 \%$, respectively. In contrast, the n-type device exhibited the significant reduction of efficiency $\left(14.4 \mathrm{~cd} / \mathrm{A}\right.$ and $3.8 \mathrm{~lm} / \mathrm{W}$ at $\left.80 \mathrm{~mA} / \mathrm{cm}^{2}\right)$, it was reduced to $20 \%$ and 39.6 $\%$, respectively. The superior performances of the $\mathrm{p}-\mathrm{i}-\mathrm{n}$ structure based device were attributed to the high hole injection ability of WHI112: $\mathrm{MoO}_{3}$ and high electron mobility of $\mathrm{Alq}_{3}: \mathrm{Liq}$, leading to high power efficiency and low driving voltage. A better balance of electrons and holes could contribute to a good current efficiency for the device. These findings strongly indicated that carrier injection ability and balance showed significant affects on the performance of OLED.
\end{abstract}

Keywords: Highly efficient OLEDs, hybrid white OLEDs, p-i-n OLED.

\section{INTRODUCTION}

Since the discovery of the efficient organic light-emitting diodes (OLEDs) considerable interest has been increased in developing OLEDs with high efficiency, low operating voltage for display applications is concerned [1]. Much effort has been expanded for improving the OLED performance by modifying its structure to achieve the effective and balanced carrier injection. The carrier injections from electrodes are dependent on the energy barrier height at the interfaces between the electrodes and organic layers [2,3]. Reasonable charge carrier control in the OLED emitting layers (EMLs) is a key factor in OLED low driving voltage and high efficiency structure design. Two approaches are most frequently used to overcome the driving voltage problem. The first approach involves with inserting a thin layer as an anode buffer layer between the indium tin oxide (ITO) and hole transport layer (HTL). This buffer layer reduces the energy barrier and enhancesthe charge injection at the interface and ultimately reduces the driving voltage improving the device power efficiency [4-7]. The second method involves the use of strong electron acceptor and donor materials as dopants in the organic HTL and electron transport layer (ETL) [8,9]. Great efforts have been carried out to enhance n-doping electron transport conductivity [10]. DING et al. [11] have demonstrated the significantly enhanced device performance by combination of Lithium hydride (LiH) doped 8hydroxyquinoline aluminum $\left(\mathrm{Alq}_{3}\right)$ as a electron transport layer (ETL). However, a few studies have been reported using 8-hydroxy-quinolinato lithium (Liq) as the electron injection layer [12]. The p-doping of HTL for enhancing the hole injection and lowering the drive voltages in OLEDs has attracted much attention [13]. The p-doping HTL is typically made by co-evaporating the hole transporting materials with a strong electron acceptor like the molybdenum trioxide $\left(\mathrm{MoO}_{3}\right)$ [14] and the tetrafluro- tetracyano-quinodimethane $\left(\mathrm{F}_{4}{ }^{-}\right.$ TCNQ) [15]. The p-doping could also achieve the ohmic conductivity to minimize the voltage drop across 
the ITO/HTL interface. Judicious control of doping levels can also lead to the efficient carrier injection by the tunneling [16]. It is very difficult to balance the holes and electrons in the emitting layer, because hole mobility is generally faster than the electron mobility in organic materials. In order to solve this problem, several kinds of HTL, ETL, hole block layer and electron block layer have been studied [17,18].

In this paper, we have demonstrated hybrid white organic light-emitting diode (WOLEDs) devices based on the p-i-n structure with Liq doped into $\mathrm{Alq}_{3}$ as the n-doping layer and $\mathrm{MoO}_{3}$ doped into WHI112 as the p-doping layer. In order to reduce the driving voltage and improve efficiency, we use $\mathrm{MoO}_{3}$ doped into WHI112 as the p-doping layer and Liq doped into $\mathrm{Alq}_{3}$ as the n-doping layer, power efficiency and carrier balance have been overwhelmingly improved. The electrical engineering and hybrid WOLED charge balance are developed based on these experimental results. The mechanism of such improvement is also discussed on these experimental results.

\section{MATERIALS AND METHODS}

Glass coated with indium-tin oxide (ITO) was used as the starting substrate. The substrate was immersed sequentially in acetone and isopropyl alcohol under the ultrasonic bath for $15 \mathrm{~min}$ each, following by rinsing in DI water. The substrates were dried with nitrogen gas. Then the samples were treated with the oxygen plasma for $1 \mathrm{~min}$. prior to use. The devices were prepared by the vapor deposition onto the ITO coated glass substrate. Firstly, the series of electron-only devices were fabricated in order to obtain some data on the electron transport ability of $\mathrm{Alq}_{3}$ doped with Liq layers. The structures of electron-only devices were as follows: ITO/Alq 3 : x wt.\% Liq $(30 \mathrm{~nm}) / \mathrm{Al}(130 \mathrm{~nm})$, where $\mathrm{x}$ was $0 \mathrm{wt} . \%$ for device E-1, $10 \mathrm{wt} \%$ for device E-2, 33 wt.\% for device E-3, and 50 wt.\% device E-4 (Table 1). Secondly, the study of hole-injection ability of WHI1 12 doped with $\mathrm{MoO}_{3}$ layer, the series of hole-only devices were fabricated. Hole-only device got the following structures: ITO/ WHI112: y wt $\% \mathrm{MoO}_{3}(50 \mathrm{~nm}) / \mathrm{HTG}-1(15 \mathrm{~nm}) / \mathrm{Al}(130 \mathrm{~nm})$, y was 0 wt.\% for device H-1, 10 wt.\% for device H-2, 20 wt.\% for device H-3, and 30 wt.\% for device H-4 (Table 2).

Table 1: The parameters of electron-only devices.

\begin{tabular}{|c|c|c|c|c|}
\hline \multirow[b]{2}{*}{ DEVICE } & \multirow[t]{2}{*}{ ANODE } & \multicolumn{2}{|c|}{ n-TYPE } & \multirow{2}{*}{$\frac{\text { CATHODE }}{\mathrm{Al}}$} \\
\hline & & $\mathrm{Alq}_{3}$ & $\mathrm{Liq}$ & \\
\hline E-1 & ITO & $30 \mathrm{~nm}$ & $0 \%$ & $130 \mathrm{~nm}$ \\
\hline E-2 & ITO & $30 \mathrm{~nm}$ & $10 \%$ & $130 \mathrm{~nm}$ \\
\hline E-3 & ITO & $30 \mathrm{~nm}$ & $33 \%$ & $130 \mathrm{~nm}$ \\
\hline E-4 & ITO & $30 \mathrm{~nm}$ & $50 \%$ & $130 \mathrm{~nm}$ \\
\hline
\end{tabular}

Table 2: The parameters of hole-only devices.

\begin{tabular}{|c|c|c|c|c|c|}
\hline \multirow[t]{2}{*}{ DEVICE } & \multirow[t]{2}{*}{ ANODE } & \multicolumn{2}{|c|}{ p-TYPE } & \multirow{2}{*}{$\begin{array}{c}\text { HTL } \\
\text { HTG-1 }\end{array}$} & \multirow{2}{*}{$\begin{array}{c}\text { CATHODE } \\
\mathrm{Al}\end{array}$} \\
\hline & & WHI112 & $\mathrm{MoO}_{3}$ & & \\
\hline H-1 & ITO & $50 \mathrm{~nm}$ & $0 \%$ & $15 \mathrm{~nm}$ & $130 \mathrm{~nm}$ \\
\hline $\mathrm{H}-2$ & ITO & $50 \mathrm{~nm}$ & $10 \%$ & $15 \mathrm{~nm}$ & $130 \mathrm{~nm}$ \\
\hline $\mathrm{H}-3$ & ITO & $50 \mathrm{~nm}$ & $20 \%$ & $15 \mathrm{~nm}$ & $130 \mathrm{~nm}$ \\
\hline $\mathrm{H}-4$ & ITO & $50 \mathrm{~nm}$ & $30 \%$ & $15 \mathrm{~nm}$ & $130 \mathrm{~nm}$ \\
\hline
\end{tabular}

Finally, hybrid WOLEDs devices were fabricated with undoped, n-type and p-i-n structures. HTG-1 was used as HTL, blue host UBH15 doped with blue fluorescent dopant EB-502 as blue EML, yellow host EPH-31 doped with yellow phosphorescent dopant EPY01as yellow EML, and tris(2,4,6-trimethyl-3(pyridin-3-yl)phenyl) borane (3TPYMB) was used as hole blocking layer (HBL), while LiF and Al were used as electron injection layer and cathode, respectively. The energy band diagrams and molecular structures were displayed in Fig. 1. The structures of undoped devices was ITO/WHI112 (55 nm)/HTG-1 (10 $\mathrm{nm}) / \mathrm{UBH} 15: 3$ wt.\% EB502 (10 nm)/EPH31: 3 wt.\% EPY01 $(25 \mathrm{~nm}) / 3$ TPYMB $(10 \mathrm{~nm}) / \mathrm{Alq}_{3}(25 \mathrm{~nm}) / \mathrm{LiF}$ $(0.8 \mathrm{~nm}) / \mathrm{Al}(150 \mathrm{~nm})$. When we added $\mathrm{Alq}_{3}: 33 \mathrm{wt} . \% \mathrm{Liq}(25 \mathrm{~nm})$ and WHI112: $20 \mathrm{wt} . \% \mathrm{MoO}_{3}(55 \mathrm{~nm})$ onto the undoped devices, we obtained n-doped layer and p-doped layer (Table 3), respectively. All materials were purchased from e-Ray Optoelectronics Technology Co., Ltd., Taiwan (R.O.C.). The organic layer and 
the cathode layer were deposited under the ultrahigh vacuum chamber at $4 \times 10^{-6}$ Torr. The active area of the devices was $5 \times 5 \mathrm{~mm}^{2}$. The thickness of the organic layers was monitored by using quartz-crystal monitor. Current-voltage characteristics were measured with the computer-controlled Keithley 2400 Source Meter and elctroluminescence (EL) spectra was measured with the Spectrascan PR650 photometer. All the measurements were carried out at room temperature and atmosphere.

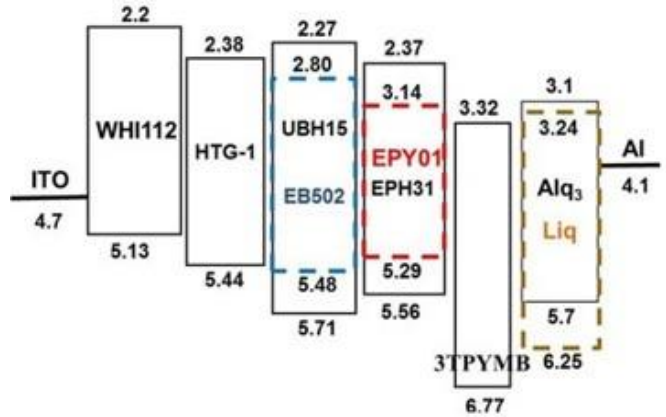

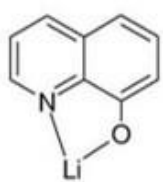

Liq

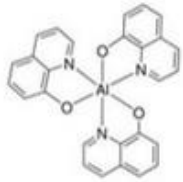

Alq,

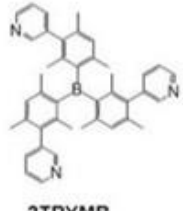

3TPYMB

Figure 1: Energy band diagrams and molecular structures of the tested materials.

Table 3: The parameters of undoped, n-doped and p-i-n devices.

\begin{tabular}{|c|c|c|c|c|c|c|c|c|c|c|c|}
\hline \multirow{2}{*}{ DEVICE } & \multirow{2}{*}{$\begin{array}{c}\text { HIL } \\
\text { WH112 }\end{array}$} & \multirow{2}{*}{$\begin{array}{c}\begin{array}{c}\text { p- } \\
\text { DOPANT }\end{array} \\
\mathrm{MoO}_{3}\end{array}$} & \multirow{2}{*}{$\begin{array}{c}\text { HTL } \\
\text { HTG-1 }\end{array}$} & \multicolumn{2}{|c|}{ BLUE EML } & \multicolumn{2}{|c|}{ YELLOW EML } & \multirow{2}{*}{$\begin{array}{c}\text { HBL } \\
\text { 3TPYMB }\end{array}$} & \multirow{2}{*}{$\begin{array}{c}\text { ETL } \\
\mathrm{Alq}_{3}\end{array}$} & \multirow{2}{*}{$\begin{array}{c}\begin{array}{c}\text { n- } \\
\text { DOPANT }\end{array} \\
\text { Liq }\end{array}$} & \multirow{2}{*}{$\begin{array}{c}\text { EIL } \\
\mathrm{LiF}\end{array}$} \\
\hline & & & & UBH15 & EB502 & EPH31 & EPY01 & & & & \\
\hline undoped & & - & & & & & & & & - & $0.8 \mathrm{~nm}$ \\
\hline $\begin{array}{c}\text { n-doped } \\
\text { p-i-n }\end{array}$ & $55 \mathrm{~nm}$ & $\begin{array}{c}- \\
20 \%\end{array}$ & $15 \mathrm{~nm}$ & $10 \mathrm{~nm}$ & $3 \%$ & $25 \%$ & $3 \%$ & $10 \mathrm{~nm}$ & $25 \mathrm{~nm}$ & $33 \%$ & - \\
\hline
\end{tabular}

\section{RESULTS AND DISCUSSION}

\subsection{Characteristics of electron-only and hole-only devices}

In electron-only device, the current density as a function of voltage $(J-V)$ characteristics at the various Liq doped into $\mathrm{Alq}_{3}$ ratios are shown in Fig. 2. In electron-only device, a rapid increasing in the device current occurs when Liq is doped into the $\mathrm{Alq}_{3}$ layer. Increasing the current density is seen when a small $10 \mathrm{wt}$ \% Liq doping concentration is introduced into the $\mathrm{Alq}_{3}$ layer, as compared with the control device. The $J-V$ characteristics of electron-only device are strongly dependent on the doping ratio in the electron transport layer. At the same voltage, the current density increases along with increasing the doping ratio. The highest current density is observed at $33 \mathrm{wt} \%$ Liq doping ratio. The E-1, E-2, E-3 and E-4 device driving voltage at 100 $\mathrm{mA} / \mathrm{cm}^{2}$ are $8,5.3,2.6$ and $6.7 \mathrm{~V}$, respectively. These electron-only device $J-V$ characteristics suggest that a certain Liq to $\mathrm{Alq}_{3}$ doping ratio could improve the co-deposited layer electron transport ability. The advantage of using $\mathrm{Alq}_{3}$ :Liq as the ETL is explained using the electron hopping exchange along with their Lowest Unoccupied Molecular Orbital (LUMO). In a single host device, electrons hop along the LUMO in $\mathrm{Alq}_{3}$. Since the LUMO-LUMO difference between $\mathrm{Alq}_{3}(3.1 \mathrm{eV})$ and Liq $(3.24 \mathrm{eV})$ is negligible, subject to their similar LUMO, transport manifolds alongwith their LUMO are expected to exhibit a certain extent of overlapping after a mixing ratio goes beyond $33 \mathrm{wt} . \%$ Liq. Therefore, it is likely that a large energetic disorder between $\mathrm{Alq}_{3}$ and Liq contributes to the electron hopping, implying that electron hopping among $\mathrm{Alq}_{3}$ and Liq sites is favorable [19]. The high electron conductivity of $\mathrm{Alq}_{3}$ :Liq might originate from the short electron transport hopping length as compared with the pure $\mathrm{Alq}_{3}$ ETL. However, the current conduction is reduced dramatically as the doping ratio is further increased to $50 \mathrm{wt} . \%$ in the device E-4. This result is attributed to the carrier quenching and defection effects.

In hole-only device, $J-V$ characteristics at various $\mathrm{MoO}_{3}$ ratios doped into WHI112 are shown in Fig. 3 . The $J-V$ characteristics of hole-only device are strongly dependent on the hole transport layer doping ratio. 
Comparing with the undoped device, we could see that the low doping strikingly decreases the driving voltage and the $J-V$ characteristics are strongly dependent on the hole injection layer doping ratio. At the same voltage, the current density increases along with increasing $\mathrm{MoO}_{3}$ doping ratio. The highest current density is observed at $20 \mathrm{wt} . \% \mathrm{MoO}_{3}$ doping ratio, indicating that the p-doping HIL layer conductivity increases due to $\mathrm{MoO}_{3}$ doping into WHI112. The H-1, H-2, H-3 and H-4 device driving voltages are 5.4, 4.3, 3.8 and $4.2 \mathrm{~V}$, respectively. The results indicate that doping $\mathrm{MoO}_{3}$ reduces the potential barrier for the hole injection at the ITO interface [20]. The hole-only device current enhancement is attributed to the reduction of resistivity and activation energy, leading to decreased ohmic losses.

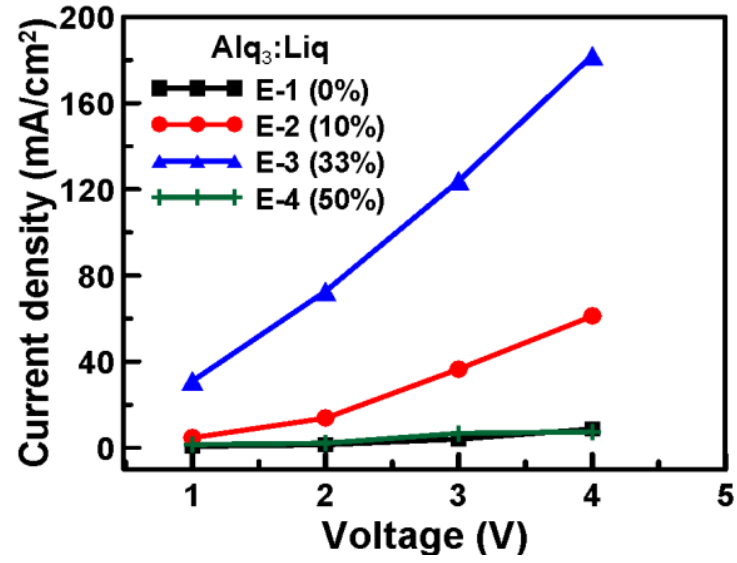

Figure 2: Electron-only $J$ - $V$ characteristics of devices E-1 to E-4.

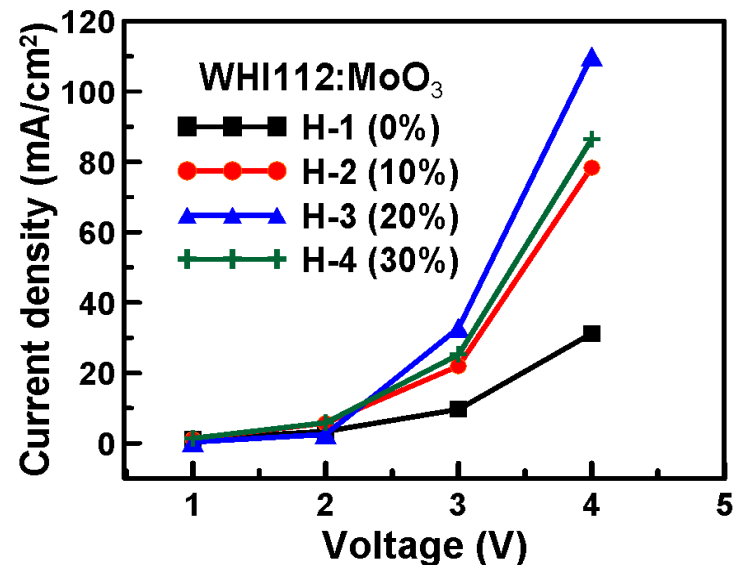

Figure 3: Hole-only $J-V$ characteristics of devices H-1 to H-4.

It is possible that the high holes are transferred from the Highest Occupied Molecular Orbitals (HOMO) in the WHI112: $\mathrm{MoO}_{3}$ matrix into the HTG-1 HOMO. The $\mathrm{MoO}_{3}(5.3 \mathrm{eV})$ and HTG-1 (5.4 eV) HOMO levels have closely energetic positions making a charge transfer and energetically favorable process. The hole transfer results in increased charge carrier concentration in the bulk HTL which increases the film conductivity and reduces HTL ohmic losses during the device operation. Through the increased bulk conductivity process, the current density is expected to increase with increasing the doping concentration. However, our devices demonstrate the reduced performance at higher $20 \% \mathrm{MoO}_{3}$ to WHI112 concentration. It is likely that because the heavy doping $\mathrm{MoO}_{3}$ molecules saturate the layer and escape into the HIL (WHI112:MoO 3 )/HTL (HTG-1) interface. This thin $\mathrm{MoO}_{3}$ layer creates a dipole barrier at the interface with HTL which increases the necessary device driving voltage. It is possible that a high $\mathrm{MoO}_{3}$ concentration might lead to significant dopant diffusion through the HTL into the EML, causing electroluminescence (EL) quenching in the emissive region. This suggests that the aggregations tend to degrade the device performance.

\subsection{Comparison between undoped and n-type devices of hybrid WOLEDs}

Hybrid WOLEDs are attracting significant attention due to their unique large-scale fabrication merits for the 
solid-state lighting sources. The yellow phosphorescent with the blue fluorescent emitter combination might result in a good compromising among the high efficiency hybrid systems. We know that in conventional devices, such as undoped device, the number of the holes is much greater than the number of the electrons. A surplus of the holes at the HTL/EML interface increases the probability that EML cations are formed, leading to the device degradation rapidly. From the electron-only device, the further experiments should focus on a device with $\mathrm{Alq}_{3}: 33 \mathrm{wt} . \% \mathrm{Liq}$ layer as the n-doping. The n-type device with $33 \mathrm{wt} . \%$ Liq doped into $\mathrm{Alq}_{3}$ as the electron carrier for hybrid WHOLEDs is therefore studied. It is very important to balance out the current supply to the emission zone. This is carried out with 3TPYMB as the electron-blocking and HTG-1 as holeblocking layers nearby the emission zone. These layers create an additional barrier for the carriers to be injected. The result shows that the recombination and/or emission zone is clearly separated from the area with the high carrier concentration. The structure of this device is ITO/WHI112 (55 nm)/HTG-1 (10 nm)/UBH15: 3 wt.\% EB502 (10 nm)/EPH31: 3 wt.\% EPY01 (25nm)/3TPYMB (10 nm)/Alq $: 0$ or 33 wt.\% Liq (25 $\mathrm{nm}) /$ with or without $\mathrm{LiF}(0.8 \mathrm{~nm}) / \mathrm{Al}(150 \mathrm{~nm})$, where $\mathrm{Liq}$ is $0 \%$ with $\mathrm{LiF}$ for undoped device and $\mathrm{Liq}$ is 33 wt. \% without LiF for n-type device. Figure 4 shows $L-V$ and $J$ - $V$ (inset) characteristics of undoped and n-type devices. The n-type device shows the lower operational voltage and higher current density and luminance slopes than the undoped device. It is clearly seen that under the same current density, the n-type device produces higher emissions than the undoped device. This represents the lower electron injection barrier and higher efficiency from the n-type device. Therefore $\mathrm{Alq}_{3}$ :Liq produces the higher electron injection efficiency and higher luminance than LiF. The power efficiency of the two devices is shown in Fig. 5. The power efficiencies of the undoped and n-type devices are 6.4 and $7.81 \mathrm{~lm} / \mathrm{W}$ at $5 \mathrm{~mA} / \mathrm{cm}^{2}$, respectively. The driving voltage of the n-type device at $5 \mathrm{~mA} / \mathrm{cm}^{2}$ is $7.2 \mathrm{~V}$, which is reduced, as compared with the undoped device (11 $\mathrm{V})$. This significant enhancement of performance is attributed to the improved transport conductivity of the n-doping Liq doped into $\mathrm{Alq}_{3}$ layer. This shows that Liq incorporation into $\mathrm{Alq}_{3}$ materials could improve device performance, by increasing the electron concentration in $\mathrm{Alq}_{3}$ films and moving the Fermi level close to the $\mathrm{LUMO}$ of $\mathrm{Alq}_{3}[19]$.

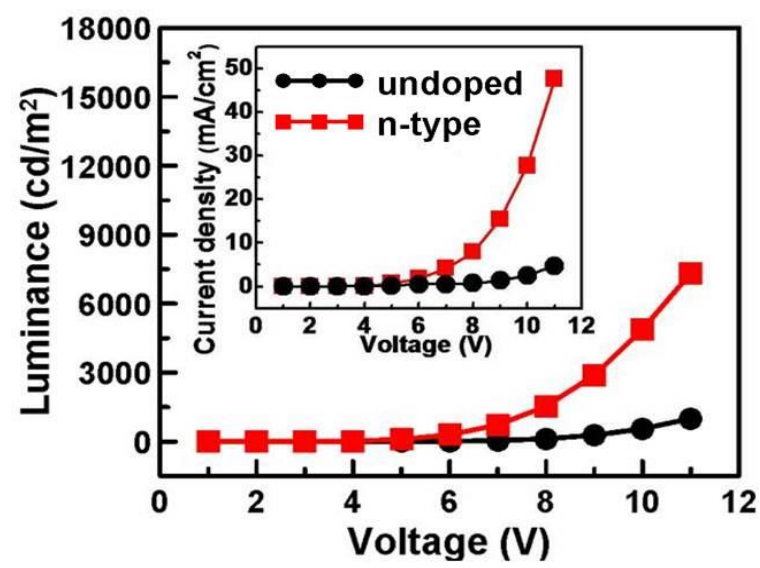

Figure 4: $L-V$ and $J-V$ (inset) characteristics of undoped and n-type devices. 


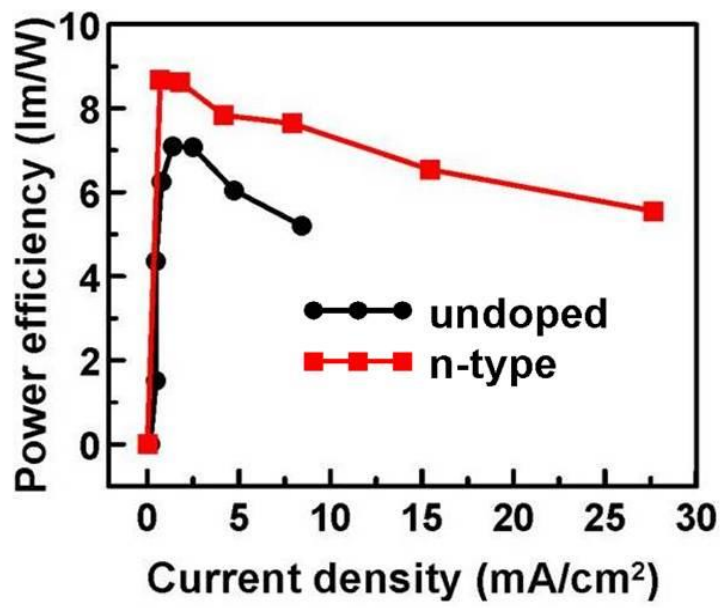

Figure 5: Power efficiency-current density characteristics of undoped and n-type devices.

\subsection{Comparison between n-typeand p-i-n devices of hybrid WOLEDs}

The power efficiency depends on the carrier injection, the transportation and the carrier balance. The p-i-n device is fabricated in which the WH112 layer is doped with 20 wt. $\% \mathrm{MoO}_{3}$ in the ITO/WHI112: 20 wt.\% $\mathrm{MoO}_{3}(55 \mathrm{~nm}) / \mathrm{HTG}-1(10 \mathrm{~nm}) / \mathrm{UBH} 15: 3$ wt.\% EB502 $(10 \mathrm{~nm}) / \mathrm{EPH} 31: 3$ wt.\% EPY01 (25nm) Alq $: 33$ wt.\% Liq $(25 \mathrm{~nm}) / \mathrm{Al}(150 \mathrm{~nm})$ configuration. The $n$-type device and $\mathrm{p}-\mathrm{i}-\mathrm{n}$ device characteristics are displayed in Figs. 6-8.

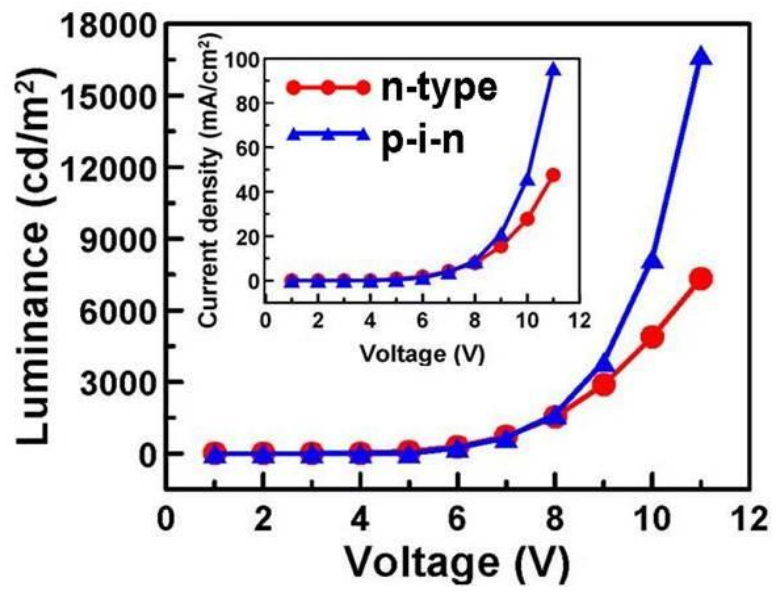

Figure 6: $L-V$ and $J-V$ (inset) characteristics of hybrid WOLEDs of n-type and p-i-n devices. 


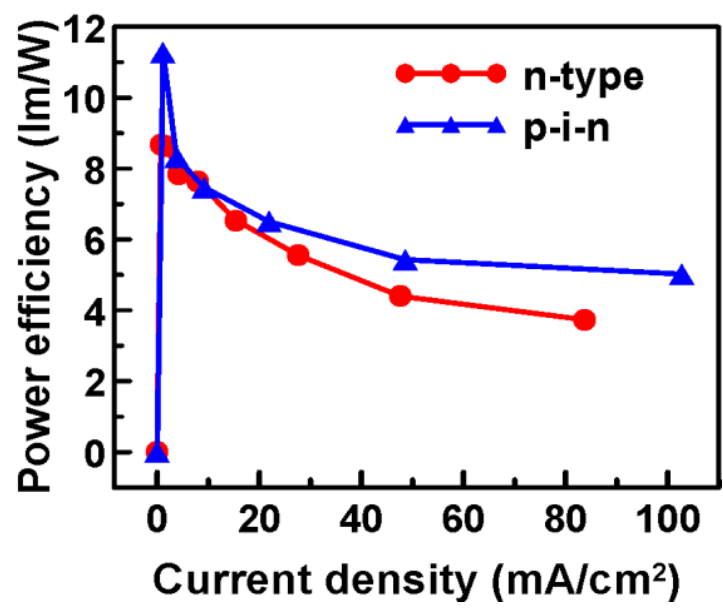

Figure 7: Power efficiency-current density character-istics of hybrid WOLEDs of n-type and p-i-n devices.

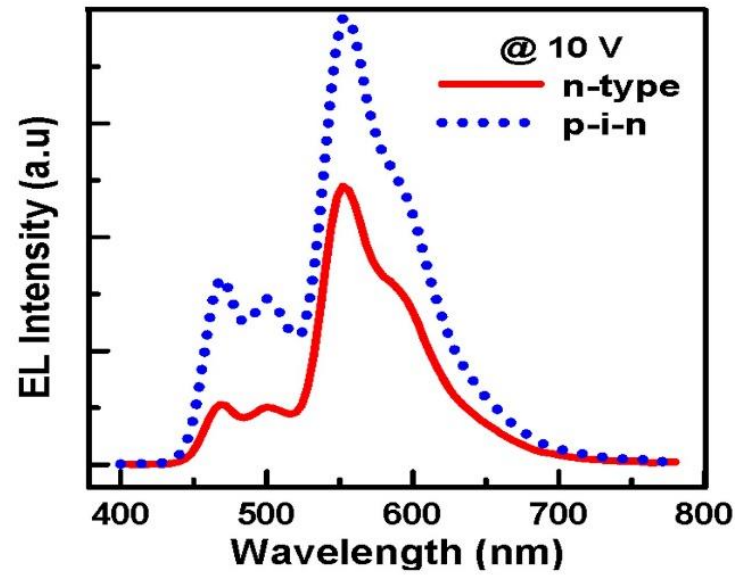

Figure 8: Electroluminescence (EL) spectra of hybrid WOLEDs of n-type and p-i-n devices.

As compared with the n-type device, the $L-V$ and $J-V$ (inset) curves of the p-i-n device are significantly enhanced, indicating that the device conductivity is improved using the p-i-n structure, as shown in Fig. 6. It is clear that the power efficiency of the $\mathrm{p}-\mathrm{i}-\mathrm{n}$ device is considerably increased as compared with the n-type device as shown in Fig. 7. This indicates the improvement of the p-i-n deviceconductivity. Table 4 summarizes the data for both devices obtained from the n-type device and $\mathrm{p}-\mathrm{i}-\mathrm{n}$ device at $20 \mathrm{~mA} / \mathrm{cm}^{2}$. The $\mathrm{p}-\mathrm{i}-\mathrm{n}$ device current efficiency, power efficiency and voltage are improved at $18.6 \mathrm{~cd} / \mathrm{A}, 6.5 \mathrm{~lm} / \mathrm{W}$ and $8.9 \mathrm{~V}$ at 20 $\mathrm{mA} / \mathrm{cm}^{2}$, respectively, as compared with the n-type device at $18 \mathrm{~cd} / \mathrm{A}, 6.3 \mathrm{~lm} / \mathrm{W}$ and $9.4 \mathrm{~V}$, respectively.

Table 4: Performance of hybrid WOLED devices at $20 \mathrm{~mA} / \mathrm{cm}^{2}$.

\begin{tabular}{cccccc}
\hline DEVICES & VOLTAGE & LUMINANCE & YIELD & POWER EFFICIENCY & CIE (X,Y) \\
\hline n-type & $9.4 \mathrm{~V}$ & $3600 \mathrm{~cd} / \mathrm{m}^{2}$ & $18.0 \mathrm{~cd} / \mathrm{A}$ & $6.3 \mathrm{~lm} / \mathrm{W}$ & $0.45,0.50$ \\
p-i-n & $8.9 \mathrm{~V}$ & $3720 \mathrm{~cd} / \mathrm{m}^{2}$ & $18.6 \mathrm{~cd} / \mathrm{A}$ & $6.5 \mathrm{~lm} / \mathrm{W}$ & $0.39,0.48$ \\
\hline
\end{tabular}

However, the roll-off of the efficiency in the p-i-n device is much smaller than the $n$-type device. The current and power efficiency of the p-i-n device are maintained with $17.2 \mathrm{~cd} / \mathrm{A}$ and $5.1 \mathrm{~lm} / \mathrm{W}$ at $100 \mathrm{~mA} / \mathrm{cm}^{2}$, it is reduced to $7.5 \%$ and $21 \%$, respectively. In contrast, the n-type device exhibits the significant reduction of efficiency $\left(14.4 \mathrm{~cd} / \mathrm{A}\right.$ and $3.8 \mathrm{~lm} / \mathrm{W}$ at $\left.80 \mathrm{~mA} / \mathrm{cm}^{2}\right)$, it is reduced to $20 \%$ and $39.6 \%$, respectively. On the other hand, for the p-i-n device, the combination of the hole-transport character of $20 \mathrm{wt} \% \mathrm{MoO}_{3}$ doped into 
WHI112 and the electron-transport property of $33 \mathrm{wt} . \%$ Liq doped into $\mathrm{Alq}_{3}$ is contributed to the controlling the holes and the electrons in the light-emitting layer and results in the stable efficiency roll-off hybrid WOLED. Figure 8 shows the EL spectra of the n-type device and p-i-n device. The EL spectrum shows the difference of the peak between these two devices. It is interesting to note that the EL spectrum of the p-i-n device is high as compared with the $\mathrm{n}$-type device. The blue peak spectrum appeared as the electron injection is increased and it shifts the recombination into the blue emission layer. This indicates that the $\mathrm{p}-\mathrm{i}-\mathrm{n}$ device plays a major impact on the hybrid WOLED optical characteristics. The CIE coordinates of the $\mathrm{n}$-typeand $\mathrm{p}$ i-n devices are $(0.45,0.50)$ and $(0.39,0.48)$, respectively, as shown in Table 1 . As the result, the p-i-n device contributes to a certain degree to the good hole-electron balance in the light-emitting layer.

\section{CONCLUSIONS}

We have presented the hybrid WOLEDs based onp-i-n structure of novel Alq 3 :Liq and WHI112: $\mathrm{MoO}_{3}$ as ntype and p-type, respectively. Current efficiency of $18.6 \mathrm{~cd} / \mathrm{A}$, power efficiency of $6.5 \mathrm{~lm} / \mathrm{W}$, and driving voltage $8.9 \mathrm{~V}$ at a current density of $20 \mathrm{~mA} / \mathrm{cm}^{2}$ in p-i-n hybrid WOLEDs were obtained. The roll-off of the efficiency in the $\mathrm{p}-\mathrm{i}$-n device was much smaller than the $\mathrm{n}$-type and undoped devices. The current and power efficiency of the p-i-n device were maintained with $17.2 \mathrm{~cd} / \mathrm{A}$ and $5.1 \mathrm{~lm} / \mathrm{W}$ at $100 \mathrm{~mA} / \mathrm{cm}^{2}$, it was reduced to $7.5 \%$ and $21 \%$, respectively. In contrast, the n-type device exhibited the significant reduction of the efficiency $\left(14.4 \mathrm{~cd} / \mathrm{A}\right.$ and $3.8 \mathrm{~lm} / \mathrm{W}$ at $\left.80 \mathrm{~mA} / \mathrm{cm}^{2}\right)$, it was reduced to $20 \%$ and $39.6 \%$, respectively. The superior performance was attributed to the high hole and electron ability of $\mathrm{WH} 112: \mathrm{MoO}_{3}$ and $\mathrm{Alq}_{3}: \mathrm{Liq}$, leading to low driving voltage and better electron and hole balance, contributing to enhanced efficiency even at the high current density. Effective carrier balance between the holes and electrons was achieved from the enhanced transport layer conductivity, leading to the device enhanced efficiency.

\section{ACKNOWLEDGMENTS}

This work is supported by King Mongkut's Institute of Technology Ladkrabang (KREF145901).

\section{BIBLIOGRAPHY}

[1] LEE, K.S., LIM, I.S., HAN, S.H., et al., "Enhancement of the power efficiency for p-i-n OLEDs containing organic p-type HAT-CN and n-type LCV materials", Organic Electronics, v. 15, n.2, pp. 343-347, Feb. 2014.

[2] YANG, J.P., BAO, Q.Y., XIAO, Y., et al., "Hybrid intermediate connector for tandem OLEDs with the combination of $\mathrm{MoO}_{3}$-based interlayer and p-type doping", Organic Electronics, v.13, n.1, pp. 2243-2249, Nov. 2012.

[3] XIE, G.H., FEHSE, K., LEO, K, et al., "Novel P-I-N-P top-emitting organic light-emitting diodes with enhanced efficiency and stability”, Organic Electronics, v. 14, pp. 2331-2340, Sep. 2013.

[4] LEE, J.H., KIM, J.W., KIM, S.Y., et al., "An organic p-n junction as an efficient and cathode independent electron injection layer for flexible inverted organic light emitting diodes", Organic Electronics, v. 13, pp. 545-549, Sep. 2012.

[5] DING, L., ZHANG, F., MA, Y., et al., "Aluminum/ $\mathrm{MoO}_{3}$ anode thin films: an effective anode structure for high-performance flexible organic optoelectronics", Journal of Semiconductors, v. 33, pp. 013003-1-4, Jan. 2012.

[6] MEYER,J., KIDAMBI, P.R., BAYER, B.C., et al., "Metal oxide induced charge transfer doping and band alignment of graphene electrodes for efficient organic light emitting diodes", Scientific Reports 4, n. 5380, pp. 1-7, Jun. 2014.

[7] ZHANG,X., YOU, F., ZHENG, Q., et al., "Solution-processed $\mathrm{MoO}_{\mathrm{x}}$ hole injection layer towards efficient organic light-emitting diode", Organic Electronics, v. 39 pp. 43-49, Sep.2016.

[8] HUH, Y.H., KWON, O.E., PARK, B., "Triple-stacked hole-selective layers for efficient solutionprocessable organic semiconducting devices", Optics Express, v. 23, n.11, pp. A625-A639, May 2015.

[9] NIKIFOROV, G.O. "Molecular p doping of 4,40-Bis(N-carbazolyl)-1,10-biphenyl and n doping of 1,3,5tris(N-phenylbenzimidazol-2-yl)benzene”, Organic Electronics,v. 36, pp.120-132, Jun. 2016.

[10] LUSSEM, B., RIEDE, M., LEO, K. "Doping of organic semiconductors", Physica Status Solidi A 210, v. 1, pp. 9-43, Dec. 2013.

[11] DING, L., TANG, X., XU, M.F., et al., "Lithium hydride doped intermediate connector for high- 
efficiency and long-term stable tandem organic light-emitting diodes", ACS Applied Materias \&Interfaces, v. 6, n.20, pp. 18228-18232, Oct. 2014.

[12] TSANG, D.P.-K.,MATSUSHIMA, T., ADACHI, C., “Operational stability enhancement in organic light-emitting diodes with ultrathin Liq interlayers”, Scientific Reports. v. 6, p. 22463, Mar. 2016.

[13] ZHANG, L., ZU, F.-S., DENG Y.-L., et al., "Origin of enhanced hole injection in organic light-emitting diodes with an electron-acceptor doping layer: p-type doping or interfacial diffusion", ACS Applied Materias \& Interfaces, v. 7(22), pp. 11965-11971, May 2015.

[14] ZHANG, L., ZHOU, D.-Y., WANG, B., et al., "Enhanced efficiency and stability in organic lightemitting diodes by employing a p-i-n-p structure", Applied Physics Letters, v.109, n.17, pp.173302-1173302-4, Oct. 2016.

[15]WANG, B., ZHANG, L, HU, Y., et al., "Doped hole injection bilayers for solution processable blue phosphorescent organic light-emitting diodes", Journal of. Materials Chemistry C, v. 4, pp. 6570-5674, Jun. 2016.

[16] GAO, J., NILES, E.T., GREY, J.K., Aggregates promote efficient charge transfer doping of poly(3hexylthiophene), Journal of Physical Chemistry Letters, v. 4, n.17, pp. 2953-2957, Aug. 2013.

[17] MURANO, S., PAVICIC, D., FURNO, M., et al., "Outcoupling enhancement mechanism investigation on highly efficient PIN OLEDs using crystallizing evaporation processed organic outcoupling layers", SID Symposium Digest of Technical Papers, v. 43, pp.687-690, Jun. 2012.

[18] ZHANG, D., DUAN, L., ZHANG, D., et al., "Extremely low driving voltage electrophosphorescent green organic light-emitting diodes based on a host material with small singlet-triplet exchange energy without p- or n-doping layer”, Organic Electronics, v. 14, n.1, pp. 260-266, Jan. 2013.

[19] KIM, S., CHOI, P., KIM, S., et al., "Analysis of the electrical properties of an electron injection layer in $\mathrm{Alq}_{3}$-based organic light emitting diodes", Journal of Nanoscience and Nanotechnology, v. 16(5), pp. 47424745, May 2016.

[20] QIU, Y.J., High Efficiency Organic Light Emitting Diodes with $\mathrm{MoO}_{3}$ Doped Hole Transport Layer, Master Thesis, Materials Science \& Engineering, University of Toronto, Toronto, ON M5S, Canada, 2012. 